Neurosurg Focus 23 (5):E5, 2007

\title{
Mechanisms of visual loss in papilledema
}

\author{
Clemens M. Schirmer, M.D., ${ }^{1}$ AND Thomas R. Hedges, III M.D. ${ }^{2,3}$ \\ ${ }^{1}$ Departments of Neurosurgery, ${ }^{2}$ Ophthalmology, and ${ }^{3}$ Neurology, New England Medical Center, \\ New England Eye Center, and Tufts University School of Medicine, Boston, Massachusetts
}

\begin{abstract}
$\checkmark$ The term "papilledema" indicates swelling of the optic discs secondary to increased intracranial pressure. Papilledema can be caused by an intracranial mass lesion or by other factors. Visual symptoms frequently accompany papilledema, which can lead to permanent visual loss if left untreated. Starting with an illustrative case, the authors review the pathophysiology of the visual signs and symptoms of papilledema. They also briefly review potential treatment options, focusing on the role of the neurosurgeon in the treatment of patients with papilledema.
\end{abstract} (DOI: 10.3171/FOC-07/11/E5)

KEY WORDS • intracranial hypertension • papilledema • visual loss

$\mathrm{P}$ APILLEDEMA, or swelling of the optic disc due to raised ICP, implies a certain set of possible causes from a neurosurgical perspective. Bedside examination with an ophthalmoscope in the hands of a reasonably experienced examiner can be used to detect more severe degrees of papilledema. Eponyms such as Foster-Kennedy syndrome have firmly imprinted the relationship between chronically increased ICP from a slow-growing neoplasm and the development of ipsilateral optic atrophy and contralateral papilledema as a presenting sign. Recent reviews have focused on the pathophysiology of optic disc swelling and the factors that differentiate true papilledema from optic disc swelling secondary to other causes. ${ }^{78}$

Visual loss from papilledema may occur even in cases of mild ICP elevation through a variety of pathophysiological mechanisms. In this case-based review, we focus on the mechanisms that lead to visual disturbances related to increased ICP, excluding the effects of lesions causing direct compression of the visual pathways (see summary, Fig. 1).

\section{Illustrative Case}

This 13-year-old girl presented with dizziness, lightheadedness, and "fuzzy" vision that progressed to transient visual obscurations. The transient vision loss had occurred multiple times in the preceding week, was frequently complete in one or both eyes, and lasted no more than 1 to 2 minutes. Some of the episodes were associated with standing up quickly and were occasionally associated with a

Abbreviations used in this paper: CSF = cerebrospinal fluid; $\mathrm{ICP}=$ intracranial pressure; $\mathrm{IIH}=$ idiopathic intracranial hypertension; OCT $=$ optical coherence tomography; RNFL = retinal nerve fiber layer. feeling of lightheadedness. She also complained of a contant dull left temporal pain extending from the eye to the side of the head. The patient had a history of GuillainBarré syndrome and had undergone treatment with immunoglobulin when she was 7 years of age. At that time and at follow-up a year later, ophthalmological examination had demonstrated mild myopia. The child weighed 201 pounds at presentation.

On examination, the patient had 20/20 visual acuity in both eyes, bilateral weakness of the lateral rectus muscles, and moderate papilledema in both eyes, more prominent in the right eye (Fig. 2). Enlarged blind spots were found on Humphrey visual fields analysis (Carl Zeiss Meditech) (Fig. 3, top panel).

Four days later, she awoke with an abrupt loss of the lower part of her right visual field. She was evaluated by a neurologist who found no other localizing abnormalities and made a provisional diagnosis of pseudotumor cerebri or IIH. Magnetic resonance imaging was nondiagnostic for the presence of an intracranial mass lesion, and magnetic resonance angiography showed normal veins and sinuses. A lumbar puncture revealed an opening pressure of 470 $\mathrm{mm}$ of water. The patient was started on oral acetazolamide therapy, 250-mg three times daily.

Ten days later, her visual acuity was 20/100 in the right eye and 20/20 in the left. Visual field testing revealed a large central area of visual loss in the right eye, and inferonasal depression in the left eye (Fig. 3, Day 10). A relative afferent papillary defect was present in the right eye, and the optic discs, which were congenitally crowded, were moderately swollen. Optical coherence tomography (Carl Zeiss Meditech) showed subretinal fluid in the peripapillary and submacular area in both eyes (Fig. 4). The patient's sixth cranial nerve palsies resolved after lumbar puncture.

After 2 weeks of treatment with 2 grams of acetazola- 


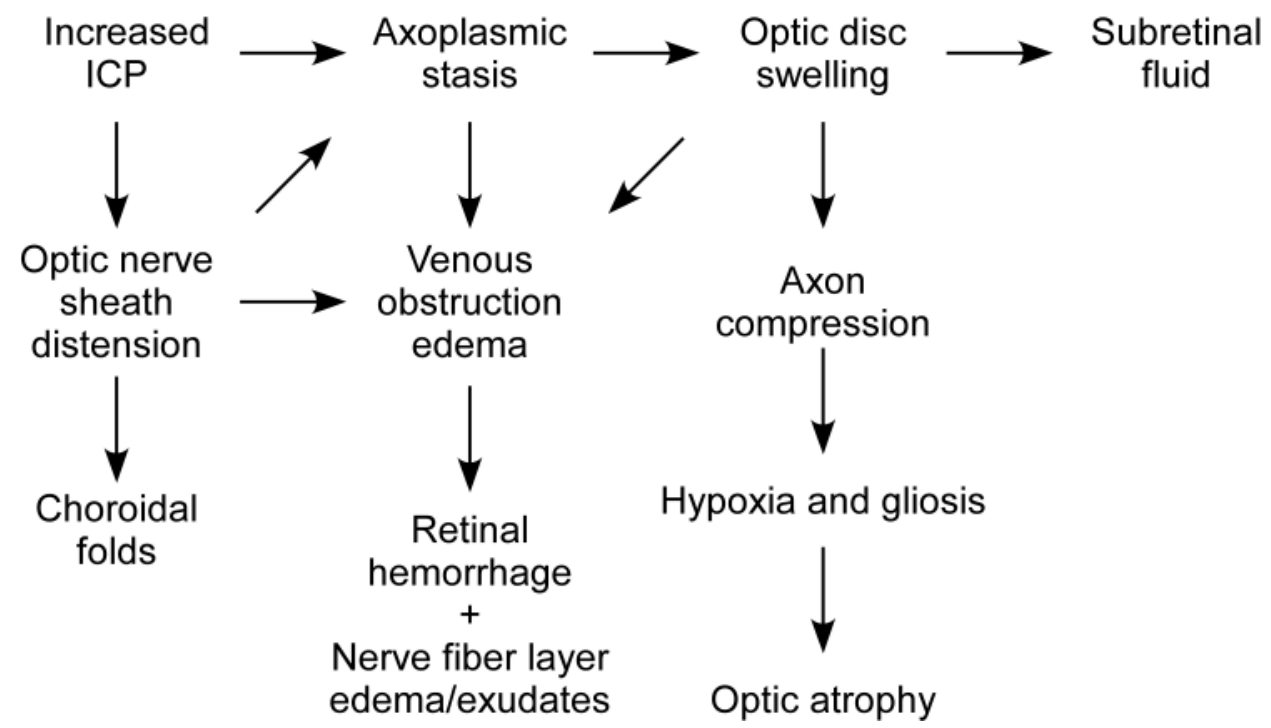

FIG. 1. Schematic diagram of the pathogenesis of papilledema based primarily on the literature dealing with its pathophysiology.

mide per day, her visual fields improved with residual inferonasal defects in both eyes (Fig. 3, Day 18); her visual acuity was 20/30 in the right eye and 20/20 in the left. One month later, her visual acuity was 20/20 in both eyes, and visual fields were somewhat better (Fig. 4D). Both optic discs were unchanged from before, although the right disc appeared pale.

\section{Conditions Causing Intracranial Hypertension}

The Monro-Kellie hypothesis postulates that the intracranial volume is composed of blood volume, CSF, and brain volume. Any addition of volume or any process blocking CSF flow will cause an increase in ICP. Conditions causing increased ICP can be grouped into four subsets: 1) increased CSF production; 2) increased vascular volume; 3) increased venous pressure with subsequent reduced CSF resorption; and 4) reduced reuptake of CSF through the Pacchionian granulations. Increased interstitial brain volume can result from the treatment of hypothyroidism, growth hormone treatment, deprivation dwarfism, or nonpulsatile cardiopulmonary bypass. The size of the cranial vault in turn may be smaller in patients with conditions that result in cranial bone thickening, such as Paget disease or bone metastasis.

True excess production of CSF occurs in choroid plexus papilloma, ${ }^{3}$ accompanied by ventricular enlargement, hydrocephalus, and elevated CSF protein levels. ${ }^{67}$ Although treatment for IIH is centered on the reduction of CSF production with diuretic agents like acetazolamide or furosemide, the existence of true CSF overproduction as a cause of pseudotumor cerebri or IIH is currently not supported by experimental or clinical data.

An increase in CSF volume is a second potential cause for IIH and has been demonstrated in experimental studies. ${ }^{7,49,60}$ Only one study, however, showed changes large enough to account for the increase in ICP seen in IIH. ${ }^{25}$ Early studies showed a linear relationship between venous pressure and ICP, but patients in these studies had few symptoms and only one had papilledema. ${ }^{17}$ In contrast, conditions that lead to venous outflow obstruction-such as radical neck dissection ${ }^{47}$ and arterialization of major venous sinuses by retrograde venous drainage in pial or dural arteriovenous malformations ${ }^{79}$ - are well-known causes of intracranial hypertension.

Conditions associated with pseudotumor cerebri or IIH are plentiful, and have been reviewed by Johnston et al., ${ }^{38}$ Sugerman, ${ }^{72}$ and Digre and Corbett. ${ }^{15}$ From a neurosurgical perspective, these include Cushing disease and exogenous corticosteroids, growth hormone-secreting pituitary adenoma or growth hormone replacement therapy, subarachnoid hemorrhage, dural sinus stenosis or thrombosis,${ }^{19}$ head injury, meningitis, sarcoidosis, leukemia, gliomatosis cerebri, and spinal cord tumors. More commonly, IIH is associated with obesity in young women and has less clear associations with birth control pills or tetracycline use. ${ }^{15}$

\section{Diagnosis of Papilledema}

\section{Fundoscopic Examination}

The ophthalmoscopic examination of most patients with increased ICP reveals papilledema. ${ }^{4}$ One must be careful in distinguishing between papilledema and pseudopapilledema caused by optic disc drusen, ${ }^{43}$ other congenital disc anomalies, hyperopic discs in young children, and myelinated nerve fibers. Features that aid in identifying true papilledema include thickening and grayness of the peripapillary nerve fiber layer, telangiectatic disc vessels, and obscuration of branch vessels at the disc margin. ${ }^{10}$

Papilledema ranges in its manifestations from slight to severe. A four-tier grading scheme ranging from slight to moderate to severe and atrophic papilledema has been used. Frisén ${ }^{18}$ proposed a grading scale from 0 to 5 that is best suited to papilledema secondary to IIH.

Papilledema that is clinically detectable can develop over 1 to 7 days of increased ICP..$^{27,29}$ In a study in monkeys, half of the monkeys with increased ICP developed pap- 


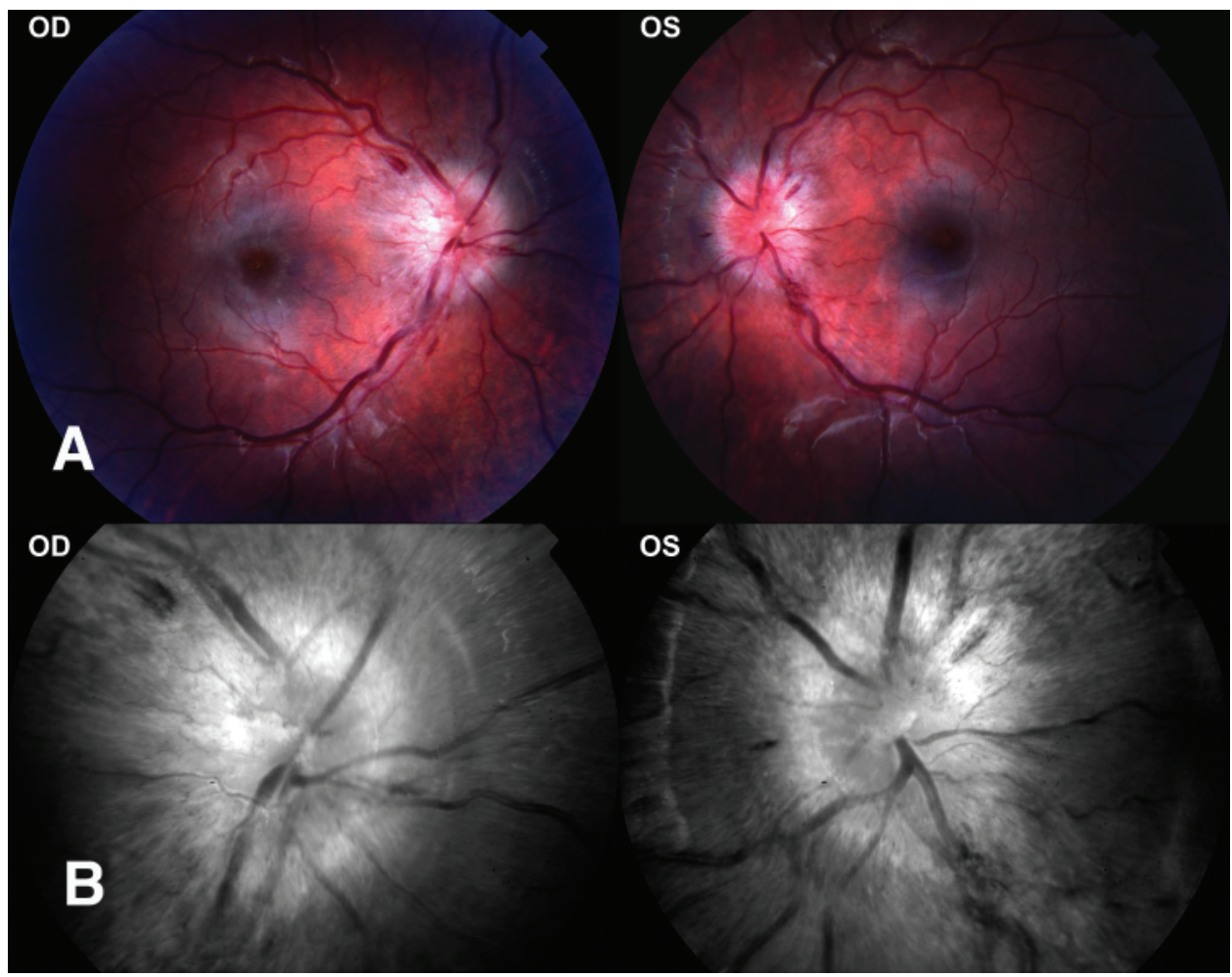

FIG. 2. Fundus photographs in the left (A) and right (B) eyes obtained on Day 11 showing moderate papilledema. Redfree views of the optic discs showing obscuration of peripapillary retinal vessels, superficial telangiectasis and flame hemorrhages. There is segmental pallor of the right disc. $\mathrm{OD}=$ oculus dextrus; $\mathrm{OS}=$ oculus sinister.

illedema within 2 days. ${ }^{27}$ In another study, papilledema did not develop acutely and was found only after 5 to 6 days. ${ }^{71}$

The swelling of the disc begins at the lower pole and progresses over the upper pole to the nasal pole. Temporal disc elevation is a later sign, and blurring of the disc margin occurs only after significant disc edema.

\section{Optical Coherence Tomography}

Optical coherence tomography ${ }^{36}$ is a recently developed technique that has become a standard for high-resolution cross-sectional retinal imaging. Imaging with OCT is analogous to the use of ultrasound B scanning in that spatial information is extracted from the time delays of reflected signals. Optical waves differ from acoustical waves in fundamental ways, including a shorter wavelength that allows for much higher (approximately $10 \mu \mathrm{m}$ ) longitudinal resolution in the retina as well as noncontact and noninvasive measurement of biological tissues. Cross-sectional imaging with OCT has been previously demonstrated in the normal human anterior ocular segment retina and retinal nerve fibers around the optic nerve. ${ }^{33}$ Optical coherence tomography allows excellent imaging of macular edema arising from conditions such as diabetes, ${ }^{34}$ as well as peripapillary and submacular fluid in patients with papilledema. ${ }^{35}$ In our patient, OCT demonstrated changes consistent with disc swelling and the presence of peripapillary and submacular fluid (Fig. 3B and C). Optical coherence tomography has also been used to evaluate the nerve fiber layer in mild papilledema. ${ }^{35,42,66}$ Because OCT can quantify retinal and optic nerve structure, it can be useful in the long-term follow-up of patients with papilledema. ${ }^{30}$

\section{Pathophysiology of Papilledema}

Although the definitive pathogenesis of papilledema in response to increased ICP remains unclear (Fig. 1), the prevailing theory is that papilledema is primarily a mechanical nonvascular phenomenon. ${ }^{28,82}$ A successful theory should be able to explain the occurrence of transient visual obscurations, swelling localized to the optic disc, venous distension, absence of spontaneous venous pulsations, and relative sparing of the papillomacular bundle. ${ }^{81}$ The severity of papilledema is related to the ICP increase, but may not correlate directly with the level of ICP because the communication of CSF pressure between the optic canal and the intracranial space depends on an open CSF space surrounding the optic nerve, ${ }^{76}$ which varies in width from patient to patient. Increased ICP in the optic nerve sheath produces axoplasmic flow stasis in the optic disc with subsequent swelling of the axons. This manifests as early papilledema and secondarily causes changes in the other optic disc as wll as retinal vascular changes associated with papilledema. This phenomenon was experimentally reproduced by direct ligation of the optic nerve, and the use of intracranial balloons to cause increased ICP ${ }^{82}$ or by induced ocular hypotension. ${ }^{77}$

The role of central retinal venous pressure in the pathophysiology of papilledema remains unclear. The subarachnoid course of the central retinal vein could explain the dis- 
appearance of venous pulsations with increased ICP, but experimental compression of the central retinal vein did not produce papilledema. ${ }^{28}$ Perhaps axonal swelling secondarily causes venous congestion with subsequent development of intracellular fluid. ${ }^{68}$ Another finding in papilledema is the development of opticociliary shunt vessels, which reflects progressive occlusion of the central retinal vein with diversion of the retinal venous outflow into the vortex/ciliary circulation..$^{10}$ In cases of very severe and acute increased ICP, usually due to subarachnoid hemorrhage, retinal and vitreous hemorrhages can occur (Terson syndrome). This is probably due to massively increased intracranial and orbital venous pressure,,$^{32}$ although it could also be due to distortion of peripapillary vascular anatomy. ${ }^{54}$

\section{Mechanisms of Visual Loss}

Papilledema causes a number of effects on the visual system, the most severe of which is nerve fiber dysfunction from swelling, subsequent and progressive loss of the retinal nerve fibers, and optic atrophy. The papillomacular bundle appears spared until later stages of the disease. ${ }^{81}$ Other ocular effects of papilledema include transient and acute loss of optic nerve function and retinal dysfunction from changes in the macular region.

\section{Transient Visual Obscurations}

The pathophysiology of transient visual obscurations in patients with papilledema remains unknown. These occur in $68 \%$ of patients ${ }^{21}$ and last seconds to minutes, sometimes associated with changes in posture; these occurred in our patient. Perhaps transient visual obscurations are due to transient ischemia ${ }^{64}$ or distortion of myelin at the nodes of Ranvier, which has been shown to be a reversible cause of nerve dysfunction in experimental ligation of peripheral nerves. ${ }^{53}$ It remains unknown if transient visual obscurations have prognostic significance.

\section{Optic Neuropathy}

\section{Chronic Loss of Peripheral Retinal Nerve Fibers}

Chronic papilledema can lead to progressive and permanent loss of nerve fibers. ${ }^{77}$ Both small and large fibers within the optic disc are affected, but more peripheral nerve retinal fibers are affected earlier and to a larger extent. The characteristic visual field defects caused by papilledema are arcuate shaped, especially in the inferior periphery, and there is more prominent nerve fiber loss superiorly. ${ }^{13,31,76}$

The thickness of the RNFL has been evaluated using OCT as a valuable tool for quantitative longitudinal followup in patients with papilledema. ${ }^{66}$ Serial examinations of the RNFL may indicate a stable or declining clinical course because RNFL changes represent permanent neuronal loss. ${ }^{59}$ Optical coherence tomography may also help in determining if visual field loss is consistent with structural optic nerve damage or if the constricted visual fields are functional, since visual field loss of nonorganic causes does occur in a number of patients with apparent IIH..$^{15,48}$

The distribution of the RNFL damage in papilledema may be influenced by the asymmetric distribution of nerve
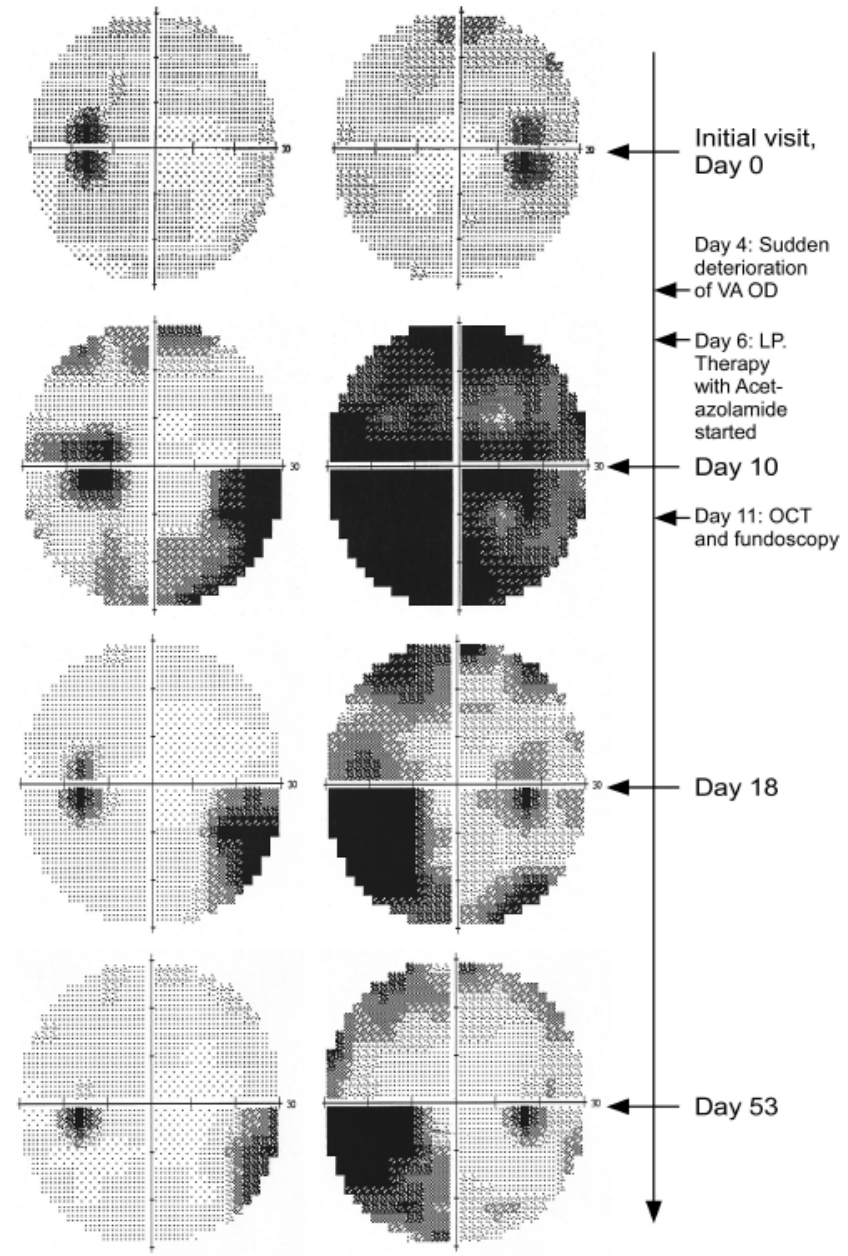

FIG. 3. Temporal progression of Humphrey visual fields in the patient described in the illustrative case. First row (Day 0): Initial enlargement of the blind spots bilaterally. Second row (Day 10): large area of central visual loss in the right field and inferonasal depression in the left. Third row (Day 18): Inferior nerve fiber bundle defects in both eyes. Fourth row (Day 53): Ongoing improvement. Arrows indicate other important events. Corresponding Snellen visual acuities are given in the right lower corner of each field. VA = visual acuity.

fiber layer diameters in different retinal regions ${ }^{76}$ and the relatively decreased glial support for nerve fiber layer bundles superior and inferior to the optic disc. ${ }^{58}$ Results showing that the neuroretinal rim of the inferior pole of the optic disc is slightly thicker than the superior pole suggest that the reserve capacity for structural deformation of the superior RNFL is low, and therefore changes in the superior RNFL are likely to predominate ${ }^{41}$ The axonal loss in the periphery of the optic nerve appeared more pronounced in one histopathological study, corresponding to the preservation of good visual acuity despite concomitant nerve atrophy ${ }^{26}$ In our case, the visual fields of the right eye probably reflect this type of nerve fiber layer loss with inferonasal defects (Fig. 3, Days 18 and 53).

\section{Acute Loss of Retinal Nerve Fibers}

Acute ischemic disc changes are an important, although 

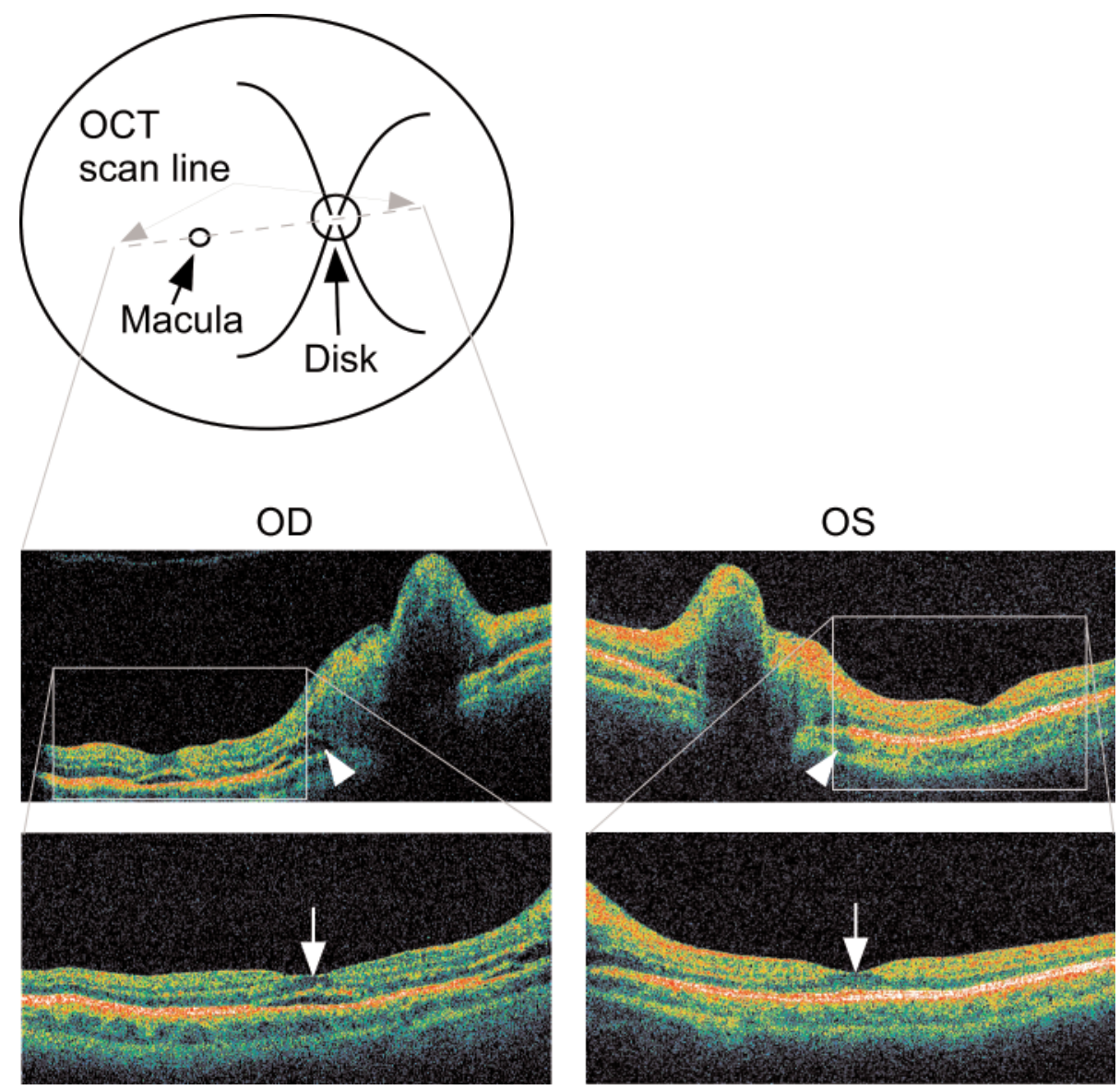

FIG. 4. A: Schematic view of the area of the fundus scanned with an OCT line scan including the macula and the optic disc. B: An OCT image showing swelling of the optic disc and peripapillary fluid (arrowheads) C: Closer view of the macular region revealing hyporeflective submacular spaces that correlate with submacular fluid (arrows).

infrequent, cause of visual loss from papilledema, and the inferior nasal field is usually affected ${ }^{31}$ Color-flow Doppler studies showed reduced blood flow in the orbit in patients with papilledema. ${ }^{51,57}$ Occasionally, the sudden loss of central vision may be attributed to an episode of ischemia in an already edematous optic nerve. ${ }^{23,75}$ In our patient, there was an acute change of vision in her right eye and much of the residual visual field loss in that eye (Fig. 3, Day 53) probably reflects ischemic optic neuropathy, superimposed on papilledema.

\section{Retinal Nerve Fiber Layer Infarcts}

Retinal nerve fiber layer infarcts are seen in severe cases of papilledema and are thought to be a minor finding of questionable relevance, in addition to the multitude of phenomena that lead to potential loss of visual function in a synergistic fashion. McLeod ${ }^{50}$ reviewed the evidence supporting the hypothesis that these infarcts are a late manifestation of transient venous hyperdistension that overwhelms the protection afforded by peripapillary axonal decompartmentalization. Cotton wool spots, commonly seen in patients with papilledema, are sentinels of this type of neuronal damage.

\section{Retinopathy}

\section{Enlargement of the Blind Spot}

Enlargement of the blind spot in patients with papilledema has been attributed to accumulation of peripapillary subretinal fluid. ${ }^{11,35,61}$ This has a prevalence of 33 to $93 \%$ in patients with IIH. ${ }^{11,31,55,80}$ However, blind spot enlargement alone usually has little clinical relevance other than reflecting the degree of optic disc swelling. Peripheral field testing is a better indicator of optic nerve integrity. ${ }^{11,31}$ The presence of peripapillary subretinal fluid has also been demonstrated in a histopathological study ${ }^{65}$ that demonstrated disruption of the intermediary tissue of Kuhnt in the presence of severe optic disc swelling with secondary influx of fluid between the retina and the retinal pigment epithelium. This phenomenon has been confirmed on fluorescein angiography. ${ }^{11}$ A hyporeflective subretinal space seen on OCT studies appears to correlate with these subretinal fluid collections. ${ }^{66}$ The initial visual fields in our patient showed enlargement of the blind spot, and OCT revealed peripapillary subretinal fluid (Fig. 4B). The source of the subretinal fluid in papilledema remains uncertain; possible sources include the vitreous humor, ${ }^{56} \mathrm{CSF}^{28}$ and the choroid plexus. ${ }^{65}$ 


\section{Macular Abnormalities}

Visual acuity is usually preserved in patients with papilledema, but macular abnormalities including choroidal folds, ${ }^{5}$ hemorrhages, ${ }^{44,75}$ macular nerve fiber layer edema, ${ }^{63}$ and subretinal fluid may affect visual acuity. Mottled macular pigmentation with preserved visual acuity may be the mildest form of permanent macular change secondary to intracranial hypertension..$^{20}$

Choroidal folds are attributed to a disproportion between the ocular contents and the scleral surroundings due to distension of the optic nerve sheath into the back of the globe. ${ }^{5}$ Bird and Sanders 5 distinguish two main types: 1) broad folding of the choroid with hyperfluorescent crests and troughs with decreased fluorescence, and 2) pigment epithelium wrinkling. The folds may lead to permanent disturbance of the choroidal pigment epithelium ${ }^{20}$ with visual loss..$^{52}$ Choroidal folds are considered risk factors for choroidal neovascularization. ${ }^{74}$

Hemorrhages into the RNFL are a constant feature of fully developed papilledema and may rarely appear in the macular region, usually with a good prognosis. ${ }^{52}$ Peripapillary hemorrhages are presumably due to abnormal permeability of the retinal capillaries and are more commonly seen. On the other hand, a rare form of hemorrhage deep to the pigment epithelium can result in major destruction of the retina and a poor prognosis..$^{52}$

Subretinal neovascular membranes are rarely seen in association with papilledema. When present, they can lead to rapid or sudden loss of vision, ${ }^{75}$ even after presumed correction of the ICP in some cases. ${ }^{2,37}$

Extensive peripapillary hemorrhages can accompany severe papilledema, and over time convert to peripapillary and macular exudates that cause persistent visual loss in patients even after resolution of the disc swelling. ${ }^{63}$ Our patient had more typical optic disc hemorrhages (Fig. 2).

\section{Retinal Nerve Fiber Layer Exudates}

As mentioned in the previous section, retinal hemorrhages may be associated with exudates in the retina, but there is another type of exudation into the RNFL of Henle, which creates a "star figure." In these cases yellowish material, possibly from the leakage of protein and lipids from capillaries on the optic disc surface, appears between the fovea and the disc. ${ }^{52}$ The presence of this material causes mild effects on vision, but is more common in severe papilledema where damage to the optic nerve predominates.

\section{Subretinal Macular Edema}

Optical coherence tomography has demonstrated the presence of submacular edema in about $10 \%$ of patients with moderate or severe papilledema (Fig. 4C) ${ }^{35}$ This edema may be due to an extension of peripapillary subretinal fluid into the macula. The fluid is probably responsible for the decreased visual acuity in a subset of patients with papilledema. In our experience, the degree of visual loss appears to correlate with the degree of macular thickening. ${ }^{35}$ The link between visual loss and subretinal edema is further corroborated by the observation that visual acuity generally improves with resolution of the subretinal edema as papilledema improves. In our patient this was seen on
OCT (Fig. 3) when her visual acuity was 20/100 in the left eye. As the papilledema and subretinal fluid resolved, her visual acuity improved to 20/20.

\section{Treatment}

Any patient with intracranial hypertension secondary to an intracranial mass lesion or obstructive hydrocephalus should undergo a thorough neurological evaluation and be considered for surgery to remedy the problem. Patients with papilledema due to meningitis can be followed as the meningitis is treated. In cases where there is no cause for the elevated ICP, as in IIH, the available options may be grouped into medical and surgical treatment modalities. Neither type of treatment should be considered to the exclusion of the other, and in practice, a combination of various options will most likely be applied.

\section{Medical Treatment}

Medical treatment options for IIH include lifestyle and diet alterations, the use of diuretics (such as acetazolamide), and in rare cases, corticosteroid therapy. Variable experiences have been reported with each of these treatments. ${ }^{15}$ The most commonly used agent in the treatment of IIH is acetazolamide, a carbonic anhydrase inhibitor that reduces CSF production and lowers intraocular pressure.

\section{Surgical Treatment}

Surgical treatment is indicated in patients with visual loss that progresses in severity or is severe on presentation. Ongoing visual loss, despite medical treatment or difficulty with medication side effects, is a common but less absolute indication for surgical treatment.

Surgical options include optic nerve sheath decompression, bariatric surgery, frequent lumbar punctures, subtemporal decompression, and the placement of lumboperitoneal shunts. The latter two are of particular interest to the neurosurgeon because urgent requests to perform such procedures may be a frequent reason for a neurosurgical consultation.

Optic Nerve Sheath Decompression. Optic nerve sheath decompression has been studied extensively. ${ }^{15}$ Based on the literature, optic nerve sheath decompression was successful with a $93 \%$ incidence of better or resolved symptoms. Ongoing visual loss is reported in 6\% of cases, and in $12 \%$ there was a need for repeated operation or the placement of a lumboperitoneal shunt in $4 \%$ of a total of 172 patients. $1,8,12,22,45,69,70$ However, there are serious side effects, including blindness from the procedure. Also, the effect on ICP is slight and headaches may persist despite surgery.

Bariatric Surgery. In our practice, bariatric surgery has been successful in many patients who could not achieve weight loss by dieting. In one study of eight severely obese patients, bariatric surgery resulted in reduction of the ICP to normal values and resolved signs and symptoms of papilledema in all patients. ${ }^{73}$

Lumbar Puncture. Serial lumbar punctures can have a failure rate up to $61 \% .{ }^{39}$ The lack of a clear end point and the transient nature of CSF drainage, combined with ongoing patient discomfort and associated compliance problems, makes this option less appealing for severe and 
chronic cases. In our practice we hardly ever resort to serial lumbar punctures.

Subtemporal Decompression. Subtemporal decompression dates back to the days of Horsley, Cushing, and Dandy. ${ }^{14}$ More recent series showed normalization of visual function in $66 \%$ of cases and the need for additional treatment in $30 \%$ in a total of 70 patients with severe complications, including seizures, hemiparesis, death, and meningitis in 15 of 43 patients. ${ }^{6,24,39,40}$ This procedure is rarely used at this time.

Lumboperitoneal Shunt Placement. The placement of a lumboperitoneal shunt is the procedure preferred by many surgeons today. An average of 2.5 shunt revisions was necessary per patient (in $45 \%$ of patients the initial procedure was sufficient) and symptoms resolved in $72 \%$ of 130 patients, with a normal visual outcome in $62 \%$ of patients in one study. ${ }^{9}$ Complications of shunt placement included shunt failure in $61 \%$ with reoperation in $55 \%$, intracranial hypotension in $22 \%$, radiculopathy, and infection. ${ }^{9,16,40,62,72}$ In extremely rare cases, shunt failure has been associated with severe and sudden visual loss. ${ }^{46}$

\section{Conclusions}

Papilledema can be caused by a variety of intracranial conditions and reflects the associated increased ICP; it can also cause sudden or chronic visual loss through a multitude of pathophysiological mechanisms. Papilledema should not be regarded as a benign condition. Treatment options include medical and surgical modalities. Neurosurgical expertise may contribute to the management of these patients when CSF diversion or decompressive procedures are indicated because of the risk of severe or progressive visual loss.

\section{References}

1. Acheson JF, Green WT, Sanders MD: Optic nerve sheath decompression for the treatment of visual failure in chronic raised intracranial pressure. J Neurol Neurosurg Psychiatry 57: 1426-1429, 1994

2. Akova YA, Kansu T, Yazar Z, Atabay C, Karagoz Y, Duman S: Macular subretinal neovascular membrane associated with pseudotumor cerebri. J Neuroophthalmol 14:193-195, 1994

3. Anderson DR, Falcone S, Bruce JH, Mejidas AA, Post MJ: Radiologic-pathologic correlation. Congenital choroid plexus papillomas. AJNR Am J Neuroradiol 16:2072-2076, 1995

4. Aulhorn E: Ophthalmological features of pseudo-tumor cerebri. Report on 18 cases. Doc Ophthalmol 58:25-33, 1984

5. Bird AC, Sanders MD: Choroidal folds in association with papilloedema. Br J Ophthalmol 57:89-97, 1973

6. Bradshaw P: Benign intracranial hypertension. J Neurol Neurosurg Psychiatry 19:28-41, 1956

7. Brooks DJ, Beaney RP, Leenders KL, Marshall J, Thomas DJ, Jones T: Regional cerebral oxygen utilization, blood flow, and blood volume in benign intracranial hypertension studied by positron emission tomography. Neurology 35:1030-1034, 1985

8. Brourman ND, Spoor TC, Ramocki JM: Optic nerve sheath decompression for pseudotumor cerebri. Arch Ophthalmol 106: 1378-1383, 1988

9. Burgett RA, Purvin VA, Kawasaki A: Lumboperitoneal shunting for pseudotumor cerebri. Neurology 49:734-739, 1997

10. Carter JE, Merren MD, Byrne BM: Pseudodrusen of the optic disc. Papilledema simulating buried drusen of the optic nerve head. J Clin Neuroophthalmol 9:273-276, 1989
11. Corbett JJ, Jacobson DM, Mauer RC, Thompson HS: Enlargement of the blind spot caused by papilledema. Am J Ophthalmol 105:261-265, 1988

12. Corbett JJ, Nerad JA, Tse DT, Anderson RL: Results of optic nerve sheath fenestration for pseudotumor cerebri. The lateral orbitotomy approach. Arch Ophthalmol 106:1391-1397, 1988

13. Corbett JJ, Savino PJ, Thompson HS, Kansu T, Schatz NJ, Orr LS, et al: Visual loss in pseudotumor cerebri. Follow-up of 57 patients from five to 41 years and a profile of 14 patients with permanent severe visual loss. Arch Neurol 39:461-474, 1982

14. Dandy WE: Intracranial pressure without brain tumor: Diagnosis and treatment. Ann Surg 106:492-513, 1937

15. Digre KB, Corbett JJ: Idiopathic intracranial hypertensions (pseudotumor cerebri): a reappraisal. Neurologist 7:2-67, 2001

16. Eggenberger ER, Miller NR, Vitale S: Lumboperitoneal shunt for the treatment of pseudotumor cerebri. Neurology 46:1524-1530, 1996

17. Friedfeld L, Fishberg AM: The relation of the cerebrospinal and venous pressures in heart failure. J Clin Invest 13:495-501, 1934

18. Frisén L: Swelling of the optic nerve head: a staging scheme. J Neurol Neurosurg Psychiatry 45:13-18, 1982

19. Gettelfinger DM, Kokmen E: Superior sagittal sinus thrombosis. Arch Neurol 34:2-6, 1977

20. Gittinger JW Jr, Asdourian GK: Macular abnormalities in papilledema from pseudotumor cerebri. Ophthalmology 96: 192-194, 1989

21. Giuseffi V, Wall M, Siegel PZ, Rojas PB: Symptoms and disease associations in idiopathic intracranial hypertension (pseudotumor cerebri): a case-control study. Neurology 41:239-244, 1991

22. Goh KY, Schatz NJ, Glaser JS: Optic nerve sheath fenestration for pseudotumor cerebri. J Neuroophthalmol 17:86-91, 1997

23. Green GJ, Lessell S, Loewenstein JI: Ischemic optic neuropathy in chronic papilledema. Arch Ophthalmol 98:502-504, 1980

24. Greer M: Management of benign intracranial hypertension (pseudotumor cerebri). Clin Neurosurg 15:161-174, 1968

25. Gross CE, Tranmer BI, Adey G, Kohut J: Increased cerebral blood flow in idiopathic pseudotumor cerebri. Neurol Res 12:226-230, 1990

26. Gu XZ, Tsai JC, Wurdeman A, Wall M, Foote T, Sadun AA: Pattern of axonal loss in longstanding papilledema due to idiopathic intracranial hypertension. Curr Eye Res 14:173-180, 1995

27. Hayreh MS, Hayreh SS: Optic disc edema in raised intracranial pressure. I. Evolution and resolution. Arch Ophthalmol 95: 1237-1244, 1977

28. Hayreh SS: Optic disc edema in raised intracranial pressure. V. Pathogenesis. Arch Ophthalmol 95:1553-1565, 1977

29. Hayreh SS, Hayreh MS: Optic disc edema in raised intracranial pressure. II. Early detection with fluorescein fundus angiography and stereoscopic color photography. Arch Ophthalmol 95: 1245-1254, 1977

30. Hedges TR: Neuro-ophthalmology, in Schuman JS, Puliafito CA, Fujimoto JG (eds): Optical Coherence Tomography of Ocular Diseases, ed 2. Thorofare, NJ: Slack Inc., 2004, pp 621-630

31. Hedges TR, Legge RH, Peli E, Yardley CJ: Retinal nerve fiber layer changes and visual field loss in idiopathic intracranial hypertension. Ophthalmology 102:1242-1247, 1995

32. Hedges TR Jr, Walsh FB: Optic nerve sheath and subhyaloid hemorrhage as a complication of angiocardiography. AMA Arch Ophthalmol 54:425-427, 1955

33. Hee MR, Izatt JA, Swanson EA, Huang D, Schuman JS, Lin CP, et al: Optical coherence tomography of the human retina. Arch Ophthalmol 113:325-332, 1995

34. Hee MR, Puliafito CA, Wong C, Duker JS, Reichel E, Rutledge B, et al: Quantitative assessment of macular edema with optical coherence tomography. Arch Ophthalmol 113:1019-1029, 1995

35. Hoye VJ III, Berrocal AM, Hedges TR III, Amaro-Quireza ML: Optical coherence tomography demonstrates subretinal macular edema from papilledema. Arch Ophthalmol 119:1287-1290, 2001 
36. Huang D, Swanson EA, Lin CP, Schuman JS, Stinson WG, Chang W, et al: Optical coherence tomography. Science 254:1178-1181, 1991

37. Jamison RR: Subretinal neovascularization and papilledema associated with pseudotumor cerebri. Am J Ophthalmol 85:78-81, 1978

38. Johnston I, Hawke S, Halmagyi M, Teo C: The pseudotumor syndrome. Disorders of cerebrospinal fluid circulation causing intracranial hypertension without ventriculomegaly. Arch Neurol 48:740-747, 1991

39. Johnston I, Paterson A, Besser M: The treatment of benign intracranial hypertension: a review of 134 cases. Surg Neurol 16: 218-224, 1981

40. Johnston IH, Sheridan MM: CSF shunting from the cisterna magna: a report of 16 cases. Br J Neurosurg 7:39-43, 1993

41. Jonas JB, Nguyen NX, Naumann GO: The retinal nerve fiber layer in normal eyes. Ophthalmology 96:627-632, 1989

42. Karam EZ, Hedges TR: Optical coherence tomography of the retinal nerve fiber layer in mild papilloedema and pseudopapilloedema. Br J Ophthalmol 89:294-298, 2005

43. Katz B, Van Patten P, Rothrock JF, Katzman R: Optic nerve head drusen and pseudotumor cerebri. Arch Neurol 45:45-47, 1988

44. Keane JR: Papilledema with unusual ocular hemorrhages. Arch Ophthalmol 99:262-263, 1981

45. Kelman SE, Heaps R, Wolf A, Elman MJ: Optic nerve decompression surgery improves visual function in patients with pseudotumor cerebri. Neurosurgery 30:391-395, 1992

46. Liu GT, Volpe NJ, Schatz NJ, Galetta SL, Farrar JT, Raps EC: Severe sudden visual loss caused by pseudotumor cerebri and lumboperitoneal shunt failure. Am J Ophthalmol 122:129-131, 1996

47. Marr WG, Chambers RG: Pseudotumor cerebri syndrome following unilateral radical neck dissection. Am J Ophthalmol 51: 605-611, 1961

48. Massicotte EC, Semela L, Hedges TR III: Multifocal visual evoked potential in nonorganic visual field loss. Arch Ophthalmol 123:364-367, 2005

49. Mathew NT, Meyer JS, Ott EO: Increased cerebral blood volume in benign intracranial hypertension. Neurology 25:646-649, 1975

50. McLeod D: Why cotton wool spots should not be regarded as retinal nerve fiber layer infarcts. Br J Ophthalmol 89:229-237, 2005

51. Mittra RA, Sergott RC, Flaharty PM, Lieb WE, Savino PJ, Bosley TM, et al: Optic nerve decompression improves hemodynamic parameters in papilledema. Ophthalmology 100:987-997, 1993

52. Morris AT, Sanders MD: Macular changes resulting from papilloedema. Br J Ophthalmol 64:211-216, 1980

53. Ochoa J, Fowler TJ, Gilliatt RW: Anatomical changes in peripheral nerves compressed by a pneumatic tourniquet. J Anat 113: 433-455, 1972

54. Ogawa T, Kitaoka T, Dake Y, Amemiya T: Terson syndrome: a case report suggesting the mechanism of vitreous hemorrhage. Ophthalmology 108:1654-1656, 2001

55. Orcutt JC, Page NG, Sanders MD: Factors affecting visual loss in benign intracranial hypertension. Ophthalmology 91:13031312, 1984

56. Peyman GA, Apple D: Peroxidase diffusion processes in the optic nerve. Arch Ophthalmol 88:650-654, 1972

57. Querfurth HW, Lagrèze WD, Hedges TR, Heggerick PA: Flow velocity and pulsatility of the ocular circulation in chronic intracranial hypertension. Acta Neurol Scand 105:431-440, 2002

58. Quigley HA, Addicks EM: Quantitative studies of retinal nerve fiber layer defects. Arch Ophthalmol 100:807-814, 1982

59. Quigley HA, Addicks EM, Green WR: Optic nerve damage in human glaucoma. III. Quantitative correlation of nerve fiber loss and visual field defect in glaucoma, ischemic neuropathy, papilledema, and toxic neuropathy. Arch Ophthalmol 100:135-146, 1982

60. Raichle ME, Grubb RL Jr, Phelps ME, Gado MH, Caronna JJ:
Cerebral hemodynamics and metabolism in pseudotumor cerebri. Ann Neurol 4:104-111, 1978

61. Reese AB: Peri-papillary detachment of the retina accompanying papilledema. Trans Am Ophthalmol Soc 28:341-351, 1930

62. Rosenberg ML, Corbett JJ, Smith C, Goodwin J, Sergott R, Savino $\mathrm{P}$, et al: Cerebrospinal fluid diversion procedures in pseudotumor cerebri. Neurology 43:1071-1072, 1993

63. Rush JA: Hard retinal exudates and visual loss due to papilledema. Ann Ophthalmol 14:168-172, 1982

64. Sadun AA, Currie JN, Lessell S: Transient visual obscurations with elevated optic discs. Ann Neurol 16:489-494, 1984

65. Samuels B: Histopathology of papilledema. Am J Ophthalmol 21:1242-1248, 1938

66. Savini G, Bellusci C, Carbonelli M, Zanini M, Carelli V, Sadun AA, et al: Detection and quantification of retinal nerve fiber layer thickness in optic disc edema using Stratus OCT. Arch Ophthalmol 124:1111-1117, 2006

67. Schijman E, Monges J, Raimondi AJ, Tomita T: Choroid plexus papillomas of the III ventricle in childhood. Their diagnosis and surgical management. Childs Nerv Syst 6:331-334, 1990

68. Schutta HS, Hedges TR: Fine structure observations on experimental papilledema in the rhesus monkey. J Neurol Sci 12:1-14, 1971

69. Sergott RC, Savino PJ, Bosley TM: Modified optic nerve sheath decompression provides long-term visual improvement for pseudotumor cerebri. Arch Ophthalmol 106:1384-1390, 1988

70. Spoor TC, Ramocki JM, Madion MP, Wilkinson MJ: Treatment of pseudotumor cerebri by primary and secondary optic nerve sheath decompression. Am J Ophthalmol 112:177-185, 1991

71. Steffen H, Eifert B, Aschoff A, Kolling GH, Volcker HE: The diagnostic value of optic disc evaluation in acute elevated intracranial pressure. Ophthalmology 103:1229-1232, 1996

72. Sugerman HJ: Lumboperitoneal shunting for pseudotumor cerebri. Neurology 50:835-836, 1998

73. Sugerman HJ, Felton WL III, Salvant JB Jr, Sismanis A, Kellum JM: Effects of surgically induced weight loss on idiopathic intracranial hypertension in morbid obesity. Neurology 45: 1655-1659, 1995

74. Talks SJ, Mossa F, Elston JS: The contribution of macular changes to visual loss in benign intracranial hypertension. Eye 12:806808, 1998

75. Troost BT, Sufit RL, Grand MG: Sudden monocular visual loss in pseudotumor cerebri. Arch Neurol 36:440-442, 1979

76. Tso MO, Hayreh SS: Optic disc edema in raised intracranial pressure. III. A pathologic study of experimental papilledema. Arch Ophthalmol 95:1448-1457, 1977

77. Tso MO, Hayreh SS: Optic disc edema in raised intracranial pressure. IV. Axoplasmic transport in experimental papilledema. Arch Ophthalmol 95:1458-1462, 1977

78. Van Stavern GP: Optic disc edema. Semin Neurol 27:233-243, 2007

79. Viñuela F, Fox AJ, Pelz DM, Drake CG: Unusual clinical manifestations of dural arteriovenous malformations. J Neurosurg 64: 554-558, 1986

80. Wall M, George D: Idiopathic intracranial hypertension. A prospective study of 50 patients. Brain 114:155-180, 1991

81. Wall M, George D: Visual loss in pseudotumor cerebri. Incidence and defects related to visual field strategy. Arch Neurol 44: 170-175, 1987

82. Wirtschafter JD, Rizzo FJ, Smiley BC: Optic nerve axoplasm and papilledema. Surv Ophthalmol 20:157-189, 1975

Manuscript submitted August 14, 2007.

Accepted September 14, 2007.

Address correspondence to: Thomas R. Hedges III, M.D., New England Eye Center, 750 Washington Street, Box 450, Boston, Massachussetts 02111. email: thedges@tufts-nemc.org. 